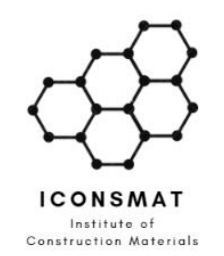

Content list available at ICONSMAT

Journal of Construction Materials

Journal homepage: www.iconsmat.com.au/publication
Article history:

Received 5 October 2020

Received in revised form

15 November 2020

Accepted 16 November 2020

Available online

02 January 2021

\title{
An investigation into sealing materials for vacuum glazing
}

\author{
Paul Onyegbule ${ }^{1 *}$, Harjit Singh ${ }^{2}$ \\ ${ }^{1}$ Department of Mechanical Engineering, Brunel University, United Kingdom \\ ${ }^{2}$ Sustainable Technology Research Centre, Kingston University, United Kingdom \\ *Corresponding Author: E: onyegbulepaul@gmail.com
}

\begin{abstract}
Vacuum glazing is an innovative transparent thermal insulator that has application in high performance window, especially in renewable energy. Different materials as well as sealing methods have been adopted to seal windows with different temperatures. The impact of temperatures on sealing layers has been found to have significant effects on the microstructure of the seal. This paper seeks to investigate the effects of sealing materials specifically glass powder and flux compound (borax) for vacuum glazing. The findings of the experiment conducted show that the sealing material was rigid with some leakage around the edge, and we found that this could be stopped by enhancing the uniformity of the seal within the periphery. Also, we found that due to the intense tensile stress from the oven surface temperature of the seal at $200{ }^{\circ} \mathrm{C}$, a crack was observed at the side of the glass. Based on the above findings, this study concludes that a glass powder with a lower melting temperature of below $250^{\circ} \mathrm{C}$ with the addition of an adhesive (borax flux) should be used for future vacuum seals.
\end{abstract}

DOI: 10.36756/JCM.v2.2.5 @2021 Institute of Construction Materials

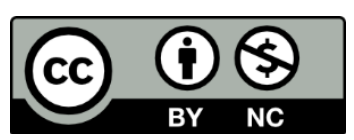

\section{Keywords}

Double glazed windows; U-value; Borax powder; Edge seal. 


\section{Introduction}

Windows consist of a glazing guided by a frame around the edge. The glass panes allow sunlight to get into the building. Vacuum glazing is an energy-saving transparent construction material with unique properties such as excellent thermal insulating property, ageing resistance, visible light transmission, and infrared light reflection. These properties originate as an outcome from a good development potential, hence making vacuum glazing using glass processing technology, an interesting area of research [1], [2]. In vacuum glazing, heat loss is one key challenges experienced by manufacturers. Basically, heat loss is experienced through the windows in different ways such as conduction, convection and radiation. Specifically, low-e coatings in the glass, play a significant role in radiative heat loss to a low vacuum space (0.1 Pa) between the two sodium glass sheets [3]. Also, in vacuum glazing, the type of seal can affect the thermal transmittance of the glass. The thermal transmittance otherwise referred to as the U-value, is one-third of that of a typical gas filled double glazing. Collins and Robison from Sydney University pioneered a study, whereby they successfully fabricated a vacuum glazing technology in 1989. The general processes involved in fabrication of window glazing is by coating round two glass panes using a sealing solder, introduced into a vacuum heating furnace for melting which seals the glass at a certain temperature. During this process, deformation could occur due to elevated temperature. This can be avoided by performing the sealing below the melting temperature of the glass. Soda lime glass has a softening temperature of about 550-600 ${ }^{\circ} \mathrm{C}$ [4]. Vacuum sealing in a kiln is carried out at low temperature to maintain shrinkage during annealing [5]. These generate stress on the sealing edge of the vacuum glazing, and if this exceeds the allowable stress of the glass or sealing layer, it will cause it to break. Additionally, the sealing solder must have a thermal expansion coefficient that is uniform to the thermal expansion of glass.

In the past, indium alloy has been used as a seal for vacuum glazing. For example, they successfully fabricated an edge seal using indium alloy material which was reported at the University of Ulster [7]. The Ulster group found out that there was a formation of micro pin holes and cracks on the seal which reduces the performance of the seal. Nonetheless, indium alloy has an advantage over the use of glass powder seal because it requires a low heating of less than $200{ }^{\circ} \mathrm{C}$. However, it is important to mention that, despite of this advantage, a technological drawback of indium alloy seal is its high price as well as its limited supply [6], [7].

Guardian industries UK, Ever-Sealed Window Inc, and a German Grenzebach GmbH company formulated the idea of using either a strip of metal or thin stainless-steel foil as a flexible edge seal, using ultrasonic bonding which has been found to withstand extreme weather conditions [4], [8]. Additionally, the stress at the edge area of the glass panes, which is caused as a result of the bonding between the flexible edge seal and the glass panes, has been found to be smaller than when using either solder glass or indium alloy edge seal [8]. What this means is that, in order to maintain a vacuum pressure of $<0.1 \mathrm{~Pa}$ on the vacuum glazing, the edge seal should be leak-free around the glass panes [4].

Currently sealing techniques focus on short term sealing performance although this depends on the chemical composition of the seal. In vacuum seals, the higher the glass contents of the composite seal, the better the leak rate. However, one of the characteristics of a good sealing solder is that it must have a thermal expansion coefficient similar to that of soda-lime glass which is $8.6 \times 10^{-6} /{ }^{\circ} \mathrm{C}$ although variation in sealing temperatures could also affect the growth form and perhaps, the grain size of the sealing solder.

During fabrication, the diffusion caused by the element affinity on the bonding interface between the solder and the glass substrate changes the sealing formation, stress, microstructure and general performance of the glass including the life span [8], [9]. Thus, vacuum glazing has a need for highperformance sealing solder and sealing technology. The present study has focused on the bearing 
stress, the residual stress of the sealing edge and heat transfer mechanisms of the vacuum glazing [10][12]. Limited results on sealing materials, manufacturing theories and design techniques have not been proven as a success and the theoretical research in this area is still at an exploratory stage.

Table 1 - Seals and properties

\begin{tabular}{|ccccc|}
\hline Type of seal & Manufacturer & $\begin{array}{c}\text { U value } \\
\left(\mathbf{W m}^{-1} \mathbf{K}^{-1}\right)\end{array}$ & $\begin{array}{c}\text { Melting } \\
\text { temperature } \\
\left({ }^{\circ} \mathbf{C}\right)\end{array}$ & $\begin{array}{c}\text { Vacuum } \\
\text { pressure (Pa) }\end{array}$ \\
\hline Indium alloy ceramic & Ulster group & 83.7 & $450-530$ & - \\
\hline Composite edge seal & - & 0.33 & 180 & $4.8 \times 10^{-2}$ \\
\hline Cerasolzer edge seal & Asahi glass company & 7.47 & $186-200$ & 0.1 or less \\
\hline Solder glass & Sydney Group & 1 & $450-530$ & - \\
\hline Laminate edge seal & $\begin{array}{c}\text { Schultz \& Jensen } \\
\text { 2008 }\end{array}$ & 0.46 & - & - \\
\hline
\end{tabular}

\section{Fabrication process}

This paper tends to discuss the process of fabrication of a vacuum seal which sustain vacuum for 0.01 Pa for a long period of time.

\section{A. Material composition}

- Two $150 \mathrm{~mm} \times 150 \mathrm{~mm}$ soda-lime float glasses with arise edges.

- Glass thickness: 4 mm

- Mix proportion of the sample: $80: 20$ and $4 \%$ quantity of water.

- $\quad 3 \sim 5 \mu \mathrm{m}$ of the borax flux.

- $\quad 3 \sim 5 \mu \mathrm{m}$ of fume silica

Table 2 - Chemical composition of glass powder

\begin{tabular}{|c|c|}
\hline Material composition & Wt.\% \\
\hline $\mathrm{Na}_{2} \mathrm{O}$ & 3.51 \\
$\mathrm{ZnO}$ & 0.52 \\
$\mathrm{MgO}$ & 0.57 \\
$\mathrm{BaO}$ & 9.4 \\
$\mathrm{PbO}$ & 0.37 \\
$\mathrm{SiO}_{2}$ & 54.1 \\
$\mathrm{Al}_{2} \mathrm{O}_{3}$ & 1.52 \\
\hline
\end{tabular}

Other properties of the glass powder include:

- Softening Point: $390{ }^{\circ} \mathrm{C}$

- Transition Point: $350^{\circ} \mathrm{C}$

- Coefficient of thermal expansion: $108 \times 10^{-7} / \mathrm{K}\left(30-300^{\circ} \mathrm{C}\right)$ 


\section{B. Preparation and evaluation of the seals}

- 100 vol. \% glass powders were mixed with water in a $100 \mathrm{ml}$ crucible.

- A commercial borax flux compound with $3 \sim 5 \mu \mathrm{m}$ of diameter was employed for the preparation of the composite seal.

- The finely ground glass powder was mixed with borax flux compound to form a paste.

- Glass cleaning around the edge seal region to avoid contamination.

- Four glass strips were placed at the side of the glass to prevent the glass powder melt from spreading all over the glass.

- The paste was applied around the edge of the assembled $150 \mathrm{~mm} \times 150 \mathrm{~mm}$ glass unit.

- The samples were prepared by sintering the compacts at $150-200{ }^{\circ} \mathrm{C}$ for $1 \mathrm{~h}$ in a conventional oven (to dry up the volatile organics before firing).

- The assembled glass unit was placed inside the oven where it was gradually heated from $30^{\circ} \mathrm{C}$ to $620^{\circ} \mathrm{C}$ at which the glass powder melts and is drawn between the two glasses. This was achieved by gradually increasing the voltage of the transformer connected to the oven.

- Pressure was applied during annealing process to keep the glass sheet at a predetermined spacing.

- After cooling, the glazing was removed from the kiln; thermal performance characterisation and visual inspection were undertaken.
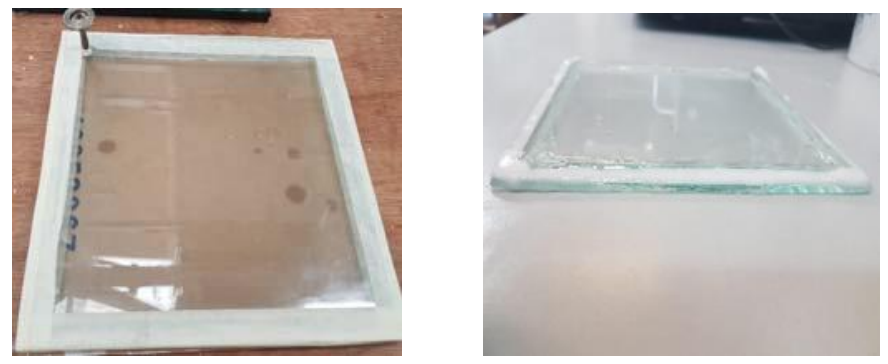

Figure 1 - Left: 90 vol.\% glass powder, 10 wt.\% borax; Right: 50 vol.\% glass powder + 50 wt.\% borax
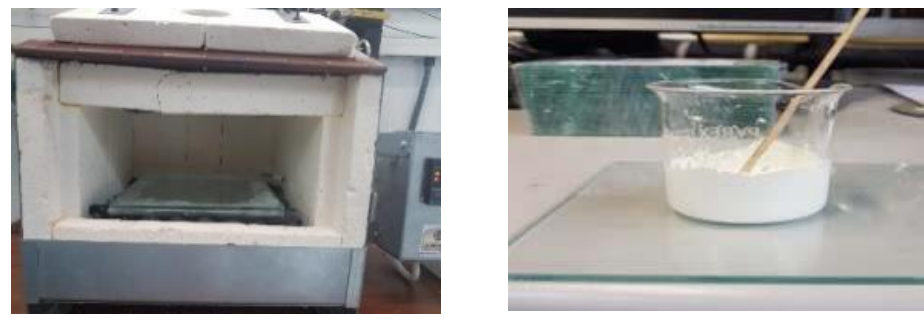

Figure 2 - Left: Kiln; Right: Sample mixture

\section{Testing}

The vacuum glazing setup was performed by first cleaning the glass sheets with solvent to avoid impurities and placing one part of the glass pane over the other. A glass strip was placed between the 
two glasses, while the seal was applied at the panes. The panes were heated in a $100-250{ }^{\circ} \mathrm{C}$ vacuum environment for 10-50 min. The glass panes were sealed with a paste as the water and organic matter were removed from the glass to form an integral part of the structure [9], [13]. The fabrication was done in two phases; Sample A and B. Sample A was more of glass powder, while B was added with addictive borax flux. The glass was cleaned to remove impurities such as oil contamination before it was introduced into the kiln. The powder quality ratio of the mixture in sample $A$ was 10:1. The sample was heated in the kiln from a temperature of $30^{\circ} \mathrm{C}$ to an elevated temperature of about $600{ }^{\circ} \mathrm{C}$. The temperature regulation was manually increased at intervals of 10 to 15 mins by gradually increasing the voltage of the transformer. The sealing properties of the fabricated seal could be analysed by carrying out a leak test. The higher the content of the glass composite seals, the lower the leak rate [14]. But, this is beyond the scope of this paper.

\section{Testing apparatus}

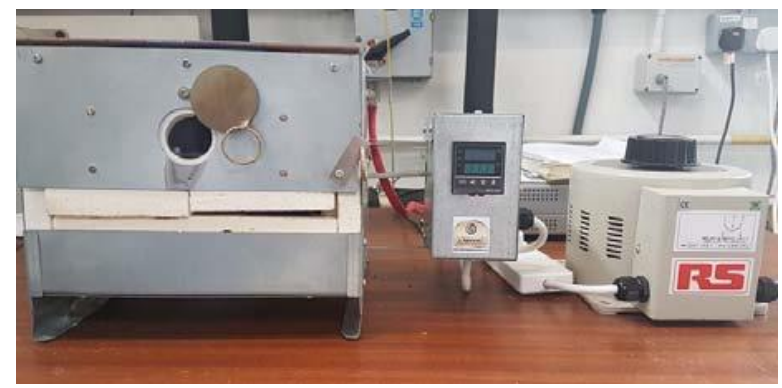

Figure 3 - Kiln with transformer

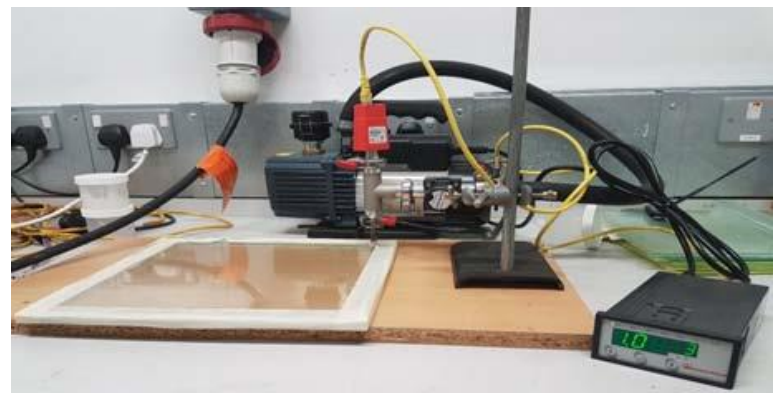

Figure 4 - Vacuum glazing system setups with sealed glass

\section{E. Results and discussions}

Table 3 - Sample A (90 wt.\% glass powder + $10 \mathrm{wt} . \%$ Borax flux) Powder quality ratio of the mixture 10:1

\begin{tabular}{|c|c|}
\hline Temp ${ }^{\circ} \mathrm{C}$ & Remark \\
\hline $\begin{array}{c}\text { 100-250 (initial preheating in a } \\
\text { vacuum environment) }\end{array}$ & Volatile organic dried up \\
$160-200$ & No observable degradation \\
$240-280$ & Partial melting of the seal \\
$260-300$ & There was a glass crack noise heard \\
$320-450$ & Seal completely melted \\
$460-580$ & Leak around the seal \\
\hline
\end{tabular}


Table 4 - Sample B (50 vol.\% glass powder + 50 wt.\% Borax flux) Powder quality ratio of the mixture 10:5

\begin{tabular}{|c|c|}
\hline Temp $^{\circ} \mathrm{C}$ & Remark \\
\hline $\begin{array}{c}\text { 100-230 (initial preheating in a } \\
\text { vacuum environment) }\end{array}$ & Volatile organic dried up \\
$160-190$ & No observable degradation \\
$200-250$ & Partial melting of the seal \\
$260-280$ & No observation \\
$290-370$ & Seal completely melted \\
$380-450$ & No crack around the seal \\
\hline
\end{tabular}

\section{F. Sealing structure}

The experiment was carried out in two phases. First, sample A comprises of 90 vol.\% glass powder plus $10 \mathrm{wt} . \%$ borax flux. Sample B, was 50 vol.\% glass powder plus $50 \mathrm{wt} . \%$ borax fluxes. Both results were tabulated in Tables III and IV, respectively. Sample B was produced at a low temperature due to the addition of addictive (borax flux). At various temperatures during the heating process, the sealing temperature was gradually increased at an interval of $30^{\circ} \mathrm{C}$ at every 10 mins. At a temperature of 240$280^{\circ} \mathrm{C}$, the connection between the glass and the sealing layer was still in contact and clear; the glass powder had not completely been melted in sample A. There were pores and cracks between the bulks and glass powder paste. The viscosity of the sealing solder was relatively large, which affects the flow of the residual gas between the particles that had not yet melted.

Pores and cracks were generated on the seal. During melting, elements from the glass powder migrated around the edges of the glass to form a wet layer within the glass strips. This reaction happened at a gradual process due to the way that the transformer was gradually increased to regulate the sealing temperature. However, the viscosity of the sealing solder gradually reduced, while temperature was increased in both samples. Pores flowed to the outside from the melting layer, due to the internal and external pressure difference within the two glasses. The glass strips between the glasses formed a barrier which did not allow the melted seal flow into the entire glass when completely melted. The transformer was increased at the interval of 10 mins which accelerated the temperature to $600^{\circ} \mathrm{C}$, resulting to a crack on the seal in sample $A$. At this stage, the element migration created a wetting layer because the glass powder paste had melted to a vitreous state. The bonding between the sealing layer and the glass became tight at a temperature of about $460-580^{\circ} \mathrm{C}$. In other words, Sample B which had more percentage of the borax flus compound had a good sealing performance. There was no pronounced bulk and the structure was in a glass liquid form. The seal began melting at $200-250^{\circ} \mathrm{C}$ and melted completely at $370^{\circ} \mathrm{C}$. The sealing temperature at this point may have caused some physical and chemical changes on the glass together with the seal. This may have also affected the migration on the sealing interface which has a significant effect on the vacuum glazing. The entire process of element migration created a chemical and physical reaction on the sealing interface which generated new matter within the edge seal of the glass panes. The generated chemical bond enhanced and strengthened the sealing between the glasses, hence improved the bonding performance between the glass and the sealing layer. At $380^{\circ} \mathrm{C}$, the glass flowed relatively well and wetted the glass material thus, contributing to a strong bond. At $400^{\circ} \mathrm{C}$, the glass began to devitrify. Temperature increase enhances the strength of the seal which would be formed. Crystals were formed which controls the thermal expansion of glass and variation of thermal expansion properties will occur with variation in heating conditions. 


\section{G. Annealing}

The samples were cooled at $10^{\circ} \mathrm{C}$ for every 5 mins. to relieve the internal stress that was formed during heating. The cooling was done to room temperature. Crack was seen during cooling in Sample A because of thermal stress. The glass bends and stretches due to the surface temperature of the kiln.

\section{Conclusion}

1. Investigation into sealing material such as glass powder and borax flux has been done in different respect. Most common material used in preparing a seal is the glass powder. It usually comes in slurry, dry or alcohol form, then broken or grounded into a quantified size. One characteristic of the sealed article of glass powder is that, in the heating and cooling and as a result, proper care must be taken during this process. Generally, glass seals are susceptible going through a section of high transitory stresses at elevated temperature. A disparity in temperature plays a key role by leading to a momentary stress during heating which lead to further compression during annealing. A reduction in the rate of firing and annealing results in a reduction of the amount of stress produced. An increase in temperature influences the strength of the seal, the chemical resistivity, thermal expansion matching the glass and low viscosity.

2. Irregularities in the changes of the seal such as tension, compression and the temperature at which the highest stress occurs in both samples. This was as a result of temperature increase which affects the durability of the seal. Choosing a material for vacuum seal, it is important to consider the stresses that cultivate during firing and annealing process.

3. The concept of using borax flux compound in fabrication of seal presented in this work lowers the melting point of the glass powder in sample B. The flux oxide serves as a good flux addictive to the glass powder which helped to fit on wet around the edges of the glass.

4. The seal bond produced on the two samples was strong. There was no crack on sample B, but rather a leakage was observed on sample $A$. This was due to the non-uniformity of the material. The crack in A was due to the temperature gradient.

5. The sealing method needs to be uniform to prevent the leak observed in sample A. In the other words, the temperature needs to be controlled in order to match the softening and melting point of the material. 


\section{Further perspectives of this research}

This section outlines the next phase of this work. First, a hardness test of the sealing layer with different sealing temperatures will be tested using a scanning electron microscope SEM. This will help to reveal more accurately, the partial cracks on the seal. A residual stress test of the sealing layers would be carried out using an electrical measuring method. The thermal performance can be improved by reducing the width of the seal and using a low-emissivity coating on the surface of the glass. At the end, the results will identify the solder sealing performance of vacuum glazing and ways of improving the manufacturing techniques.

The application of this study also expands to extra-terrestrial construction where the building internal pressure must be conserved. The use of other environmental materials are also recommended [15-30].

\section{References}

[1] R. A. Synowicki, B. D. Johs, A.C. Martin. Optical properties of soda-lime float glass from spectroscopic ellipsometry. Thin Solid Films, 519 (9) (2011), pp. 2907-29134.

[2] Luo LH, Huang ZZ, Wu YF, Cheng D, Sun LL, Cheng L, et al. Sealing properties of

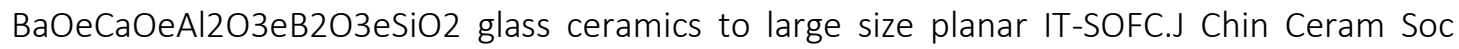
2014; 42(1):101 - 7 .

[3] Robinson SJ, Collins RE. Evacuated windows-theory and practice. In Proceeding of ISES solar world congress; 1989. Kobe, Japan: Oxford: Pergamon; 1989.

[4] Griffiths PW, di Leo M, Cartwright P, Eames PC, Yianoulis P, Leftheriotis G, et al. (1998). Fabrication of evacuated glazing at low temperature. Sol Energy; 63:243 - 9.

[5] Miao H, Xi XB, Zhang RH, Zuo DW, Wang HL. Numerical calculation and experimental research on wind load of vacuum plate glass. Acta Energise. Solaris Sin 2013; 34(11):188895.

[6] Duffie, J. and Beckman, W. (1991). Solar engineering of thermal processes. 1st edition. New York: Wiley.

[7] Eames, P. (2008). Vacuum glazing: Current performance and prospects.

[8] Fang Y, Hyde TJ, Ayra F, Hewitt N, Eames PC, Norton B, et al. Indium alloy sealed vacuum glazing development and context. Renew Sustain Energy Rev 2014; 37:480 - 502.

[9] Ng N, Collins RE, So L. Thermal conductance measurement on vacuum glazing. Int J Heat Mass Transfer 2006; 49(25 - 26):4877 - 85.

[10] Yu Li A, Du JP, Han MF, Peng SP. Structure and sealing properties of Bi2O3- EBaOeSiO2eRxOy glass. J University of Science and Technology Beijing 2011; 33(12):1529 - 35.

[11] Zhang LY, Qin ML, Qu XH, Lu YJ, Zhang XY. Study on active brazing of AIN Ceramics and Mo $\mathrm{Ni}$ - Cu alloy. Rare Metal Mater Eng 2009; 38(12):2159- 62. 
[12] Zhang RH, Ma CW, Miao H, Zhang Y, Kong DJ. Theoretical analysis and Experimental study on heat transfer in vacuum plate glass. Trans Chin Soc Agric Mach 2006; 12:134- 12.

[13] Fang, Y., Eames, P., Hyde, T. and Norton, B. (2005). Complex multilateral insulating frames for windows with evacuated glazing.

[14] Jae C, Hyuk K, Young K, Ju L and Sung P. Sealing Properties of Ceramic Fibre Composites for SOFC Application. 10.4028/www.scientific.net/SSP-126.803.

[15] A. Todhunter, M. Crowley, M. Gholamisheverini, and F. Sartipi, "Advanced technological implementation of construction and demolition waste recycling," Journal of Construction Materials, vol. 1, no. 1, 2019, doi: https://doi.org/10.36756/JCM.v1.1.3.

[16] F. Sartipi, "Automatic sorting of recycled aggregate using image processing and object detection," Journal of Construction Materials, vol. 1, pp. 3-3, 2020, doi: https://doi.org/10.36756/JCM.v1.2.1.

[17] T. Boulos, F. Sartipi, and K. Khoshaba, "Bibliometric analysis on the status quo of robotics in construction," Journal of Construction Materials, vol. 1, pp. 2-3, 2020.

[18] F. Sartipi, "A brief critical view on the carbon-conditioning of recycled aggregate using pressure chamber," Journal of Construction Materials, vol. 2, pp. 1-4, 2020, doi: https://doi.org/10.36756/JCM.v2.1.4.

[19] F. Sartipi and A. Sartipi, "Brief review on advancements in construction additive manufacturing," Journal of Construction Materials, vol. 1, pp. 2-4, 2020, doi: https://doi.org/10.36756/JCM.v1.2.4

[20] A. Gharizadeh, F. Sartipi, E. Ayoubi, and A. Severino, "The chemical reactor design configuration of $\mathrm{CO} 2$ concrete green solution," Journal of Construction Materials, vol. 1, pp. 2-5, 2020, doi: https://doi.org/10.36756/JCM.v1.2.5.

[21] A. Todhunter, M. Crowley, and F. Sartipi, "Construction productivity indices in socialism compared with capitalism," Journal of Construction Materials, 2019, doi: https://doi.org/10.36756/JCM.v1.1.2.

[22] F. Sartipi, "Diffusion of Innovation Theory in the Realm of Environmental Construction," Journal of Construction Materials, vol. 1, pp. 4-2, 2020, doi: https://doi.org/10.36756/JCM.v1.3.2.

[23] V. Tam, F. Sartipi, and K. N. Le, "Gaps between supply and demand of recycled aggregate: Sydney metropolitan case study," Presented at the CRIOCM 2018, 2018.

[24] F. Sartipi, "Influence of 5G and IoT in construction and demolition waste recycling-conceptual smart city design," Journal of Construction Materials, vol. 1, pp. 4-1, 2020, doi: https://doi.org/10.36756/JCM.v1.4.1.

[25] F. Sartipi, "Organizational structure of construction entities based on the cooperative game theory," Journal of Construction Materials, vol. 1, no. 2, 2020, doi: https://doi.org/10.36756/JCM.v1.3.3 
[26] J. Luliano, A. Singh, and F. Sartipi, "Political-economical evaluation of CO2 capture in Australian building sector," Journal of Construction Materials, vol. 1, pp. 3-2, 2020, doi: https://doi.org/10.36756/JCM.v1.3.2.

[27] F. Sartipi and E. Zarqam, "Recycled concrete and the advantages of using recycled aggregates," presented at the 3rd International congress on architecture, civil engineering and urban development, Tehran, 2016.

[28] M. Sartipi and F. Sartipi, "Stormwater retention using pervious concrete pavement: Great Western Sydney case study," Case Studies in Construction Materials, vol. 11, p. e00274, 2019.

[29] A. Todhunter, M. Crowley, F. Sartipi, and K. Jegendran, "Use of the by-products of postcombustion carbon capture in concrete production: Australian case study," Journal of Construction Materials, vol. 1, no. 1, 2019, doi: https://doi.org/10.36756/JCM.v1.1.1.

[30] F. Sartipi, K. Palaskar, A. Ergin, and U. Rajakaruna, "Viable construction technology for habitation on Mars: Fused Deposition Modelling," Journal of Construction Materials, vol. 1, no. 2, 2020. 